\title{
Como a eficiência do comportamento tático e a data de nascimento condicionam o desempenho de jogadores de futebol?
}

CDD. 20.ed. 796.073

796.33

http://dx.doi.org/10.1590/1807-55092015000300465

\author{
Marcelo Odilon Cabral de ANDRADE* \\ Israel Teoldo da COSTA*
}

*Centro de Ciências Biológicas e da Saúde, Universidade Federal de Viçosa.

\section{Resumo}

0 objetivo deste estudo foi verificar como a eficiência do comportamento tático e a data de nascimento podem condicionar o desempenho tático de jogadores de futebol. A amostra foi composta por 6640 ações táticas realizadas por 108 jogadores da categoria Sub-15. Foi utilizado o FUT-SAT para coleta e análise dos dados. A data de nascimento foi obtida através da carteira de identidade ou da certidão de nascimento. Foram utilizadas análise descritiva, teste de Regressão Logística Multinomial $(p<0,05)$ e o teste Kappa de Cohen. Para as análises estatísticas foi utilizado o software SPSS. Foram verificadas associações positivas entre a eficiência do comportamento tático e o desempenho tático para os princípios "cobertura ofensiva", "unidade ofensiva", "cobertura defensiva", "equilíbrio" e "unidade defensiva". Foram verificadas associações positivas entre a data de nascimento e o Índice de Performance Tática Defensiva em jogadores nascidos no segundo quartil. Conclui-se que para esta amostra, a eficiência do comportamento tático e a data de nascimento influenciaram o desempenho tático.

Palavras-chave: Tática; Efeito da idade relativa; Formação esportiva; Categoria de base.

\section{Introdução}

Recentemente, a literatura tem apontado que as capacidades táticas individuais e coletivas são componentes essenciais para o sucesso desportivo ${ }^{1}$. De acordo com os resultados de pesquisas, a eficiência do comportamento tático e a data de nascimento podem maximizar o desempenho tático no futebol, especialmente de jovens jogadores ${ }^{2-5}$.

De acordo com Mesquita ${ }^{6}$, a eficiência do comportamento tático está relacionada com a qualidade na execução de ações no jogo por parte do jogador. Já o desempenho tático associa-se com o resultado que estas ações provocam no jogo e nas açóes coletivas da equipe, sendo representado pela performance do jogador no jogo.

Em relação à data de nascimento, autores defendem que ela pode ocasionar diferenças no desempenho esportivo, especialmente, nos primeiros anos de formação esportiva, quando os estágios de maturidade dos jogadores encontram-se diferentes ${ }^{7-9}$. Estas diferenças no rendimento esportivo em função da heterogeneidade das datas de nascimento de determinado grupo de jogadores nascidos no mesmo ano vem sendo reportada pela literatura como o Efeito da Idade Relativa (EIR) ${ }^{10}$.

Estudos recentes mostram que o EIR está fortemente presente em todos os estágios de formação e nas equipes profissionais ${ }^{11-13}$.

Em um estudo realizado por TEOLdo et al. ${ }^{5}$ envolvendo o EIR e a eficiência do comportamento tático em jogadores de futebol com idade entre 11 e 17 anos, foi verificada uma associação positiva do desempenho tático com a data de nascimento dos jogadores e a eficiência do comportamento tático. Neste estudo ficou evidenciado que jogadores nascidos nos primeiros meses do ano (janeiro a março) tiveram um desempenho tático defensivo superior aos seus pares nascidos nos outros meses do ano, enquanto que os jogadores nascidos no último trimestre do ano (outubro a dezembro) tiveram desempenho tático ofensivo superior aos seus pares nascidos nos demais meses do ano.

Além disso, neste mesmo estudo foi verificada associação positiva entre a eficiência do comportamento tático e o desempenho tático dos jogadores em nove dos 10 princípios táticos do jogo, sugerindo 
que uma melhora na eficiência do comportamento tático promove melhoria no desempenho tático dos jogadores. Esses resultados mostraram que além do Efeito da Idade Relativa, a eficiência do comportamento tático também pode influenciar no desempenho dos jogadores.

A partir dos estudos apresentados, a investigação dos fatores que condicionam o desempenho tático dos jogadores se faz necessária, visto que nesta idade, se dá o início da fase de especialização esportiva ${ }^{14}$.

Contudo, a investigação desses fatores nesta fase de formação deve considerar a avaliação das

\section{Método}

\section{Amostra}

A amostra foi composta por 6640 açóes táticas realizadas por 108 jogadores de futebol da categoria Sub-15 de clubes e escolinhas do Estado de Minas Gerais. Para critério de seleção da amostra, os jogadores da amostra deveriam participar de treinamentos regulares (três sessóes semanais) e de torneios somente a nível regional.

As datas de nascimento dos jogadores foram distribuídas em quartis (Q) de acordo com seus respectivos anos de nascimento (1997 e 1998), sendo o Q1 referente aos meses de Janeiro a Março [ $\mathrm{n}=$ $30(27,8 \%)]$, o Q2 aos meses de Abril a Junho [n = $34(31,5 \%)$ ], o Q3 aos meses de Julho a Setembro $[\mathrm{n}=25(23,1 \%)]$ e o Q4 aos meses de Outubro a Dezembro $[\mathrm{n}=19(17,6 \%)]$.

As ações táticas realizadas pelos jogadores obtiveram as seguintes distribuiçóes, conforme os princípios táticos propostos e validados por TEOLDO et al. ${ }^{15-16}$. Princípios Ofensivos: "Penetração" [ $\mathrm{n}=254$ (3,94\%)]; "Cobertura Ofensiva" [n= 899 (13,96\%)]; "Mobilidade" [n = $130(2,02 \%)]$; "Espaço" [n= $1277(19,82 \%)]$; "Unidade Ofensiva" [n = 450 (6,98\%)]. Princípios Defensivos: "Contenção" [n= $601(9,34 \%)]$; "Cobertura Defensiva" [ $\mathrm{n}=235(3,65 \%)$ ]; "Equilíbrio" [ $\mathrm{n}=$ 660 (10,24\%)]; "Concentraçāo" [n = 608 (9,45\%)]; "Unidade Defensiva” [n = 1326 (20,60\%)].

\section{Instrumento de coleta de dados}

Para coleta e análise de dados foi utilizado o Sistema de Avaliação Tática no Futebol - FUT-SAT. Este sistema permite avaliar as açôes táticas com base em 10 princípios táticos fundamentais de jogo: a) penetração; capacidades táticas com base nos princípios táticos fundamentais do jogo de futebol, onde os jogadores de futebol nesta idade necessitam do melhor desenvolvimento desses princípios para atingirem uma alta performance no jogo ${ }^{15}$. Assim, existe a necessidade da escolha de um instrumento que considere os princípios táticos fundamentais do jogo em seu processo de avaliação.

O objetivo deste estudo foi verificar como a eficiência do comportamento tático e a data de nascimento podem condicionar o desempenho tático de jogadores de futebol.

b) cobertura ofensiva; c) mobilidade; d) espaço; e) unidade ofensiva; f) contenção; g) cobertura defensiva; h) equilíbrio; i) concentração; j) unidade defensiva.

As datas de nascimento foram coletadas com base na carteira de identidade ou certidão de nascimento dos jogadores.

\section{Procedimentos éticos}

Esta pesquisa foi aprovada pelo Comitê de Ética em Pesquisas com Seres Humanos da Universidade Federal de Viçosa (CEPH) sob o seguinte protocolo: Of. Ref. n. 099/2012/CEPH, e atende as normas estabelecidas pelo Conselho Nacional em Saúde (CNS 466/2012) e pelo Tratado de Ética de Helsinque (1996). Para a participação na pesquisa, foi utilizado um Termo de Consentimento Livre e Esclarecido (TCLE). Os responsáveis pelos clubes/escolinhas e jogadores eram contactados previamente, recebiam informaçóes sobre o procedimento da pesquisa e, posteriormente, assinavam o TCLE, se optassem por participar do estudo. Após a autorizaçáo prévia dos responsáveis, teve início a coleta de dados, sendo que a desistência de participação na pesquisa por parte dos jogadores poderia ser feita a qualquer momento.

\section{Procedimentos de coleta de dados}

Para início da coleta de dados, os pesquisadores entraram em contato com os responsáveis pelos clubes/escolinhas e o com os treinadores da categoria Sub-15. O contato foi feito através do telefone ou por visitas técnicas aos clubes/escolinhas, onde foram explicados os objetivos, procedimentos e benefícios/riscos da pesquisa. 
Como forma de avaliar os princípios táticos, foi realizado o teste de campo do FUT-SAT, o GR + 3 vs. $3+$ GR (goleiro +3 jogadores vs. 3 jogadores + goleiro). A estrutura do teste consiste em um jogo em campo reduzido (36 metros de comprimento por 27 metros de largura) onde duas equipes são divididas com três jogadores cada, mais os goleiros de cada equipe, com coletes devidamente numerados e, em seguida, são orientados a jogar por quatro minutos seguindo as regras do futebol, com a exceção da regra do impedimento. Anteriormente ao início da avaliação, são concedidos 30 segundos para "familiarização" dos jogadores com a tarefa.

Como critério de observação das ações táticas foi utilizado o conceito de posse de bola proposto por GARGANTA $^{2}$, onde a posse de bola é considerada a partir de três critérios: Finalização ao gol adversário, passe bem sucedido e pelo menos três contatos consecutivos na bola.

\section{Materiais}

Para a gravação dos jogos utilizou-se uma câmera digital SONY modelo HDR-XR100. Os vídeos coletados foram transferidos para um computador portátil modelo POSITIVO Premium 4A015RX8T, processador intel pentium dual core ${ }^{\mathrm{TM}}$, sendo convertidos para ficheiros "avi" através do programa Format Factory for Windows ${ }^{\oplus}$. Para a análise dos jogos após a coleta, utilizou-se o "software" Soccer Analyser, sendo o registro dos dados feito em uma planilha de Excel 2010 for Windows ${ }^{\circledR}$.

\section{Análise estatística}

Foi utilizada análise descritiva (média, desvio padrão, frequência e percentil) para obtenção de informaçóes a respeito da amostra.

A variável dependente do estudo foi o Índice de Performance Tática e as variáveis independentes do estudo foram a eficiência do comportamento tático e a data de nascimento dos jogadores, divida em quartis.

Para o cálculo do Índice de Performance Tática Ofensiva (IPTO) e do Índice de Performance Tática Defensiva (IPTD) foi utilizada a fórmula do Índice de Performance Tática (IPT):
IPT $=\sum$ açóes táticas (realização do princípio $\times$ qualidade da realização do princípio $\times$ localização da ação no campo de jogo $\times$ resultado da ação) / número de ações táticas.

Para o cálculo da eficiência do comportamento tático foi considerada a qualidade de realização de cada princípio tático que os jogadores realizaram, sendo utilizada a porcentagem de acerto em cada princípio tático.

A amostra foi agrupada em tercis (baixo, moderado e alto) de acordo com a eficiência do comportamento tático e o Índice de Performance Tática, sendo utilizado o tercil baixo como referência. Os clubes nos quais os jogadores atuavam foram considerados como fator secundário de agrupamento, de modo a diminuir o efeito da qualidade do treino sobre os resultados observados. Foi utilizada a Regressão Logística Multinomial $(\mathrm{p}<0,05)$ para verificar as associaçóes entre os Índices de Performance Tática e a eficiência do comportamento tático e os quartis de nascimento dos jogadores (Q1, Q2, Q3 e Q4). Foi considerado o Odds Ratio (OR) (ajustado) com intervalo de confiança de $95 \%$ para cada correlação. Para a análise estatística dos dados foi utilizado o "software" SPSS (Statistical Package for Social Sciences) for Windows ${ }^{\circledast}$, versão 18.0.

Para o cálculo da fiabilidade foi adotado o método de teste-reteste, utilizando os valores do teste de Kappa de Cohen para descrição dos resultados. As análises de fiabilidade foram realizadas respeitando um intervalo de três semanas, a fim de evitar problemas de familiaridade com a tarefa ${ }^{17}$. De um total de 6640 ações, foram reanalisadas 1260 açóes, que representam $18,97 \%$ da amostra, valor superior ao de referência $(10,00 \%)$ apontado pela literatura ${ }^{18}$. Neste procedimento participaram dois avaliadores e os valores de fiabilidade encontrados situaram entre o mínimo 0,885 (ep = 0,009) e o máximo 0,929 (ep $=0,009)$ para a fiabilidade intra-avaliador, e entre o mínimo 0,847 (ep $=0,033)$ e o máximo 0,958 $($ ep $=0,014)$ para a fiabilidade inter-avaliadores, se situando entre os valores denominados "quase perfeitos" a "perfeitos" (0,81 a 1$)$, demonstrando excelente concordância entre os avaliadores ${ }^{19}$. 


\section{Resultados}

\section{Comparação do Índice de Performance Tática Ofensiva (IPTO) entre moderado e baixo}

Os resultados indicaram que a eficiência do comportamento tático para o princípio "cobertura ofensiva" foi associada positivamente com o IPTO moderado (TABELA 1). Sendo que, jogadores que obtiveram eficiência moderada para este princípio, possuem entre 0,1 e 0,9 vezes mais chances de aumentarem o seu IPTO de baixo para moderado. Além disso, foi observado que para este princípio, os jogadores que obtiveram eficiência alta possuem entre 0,1 e 0,8 vezes mais chances de aumentarem o seu IPTO de baixo para moderado. A eficiência do comportamento tático para os princípios "penetração", "mobilidade", "espaço", "unidade ofensiva" e os quartis de nascimento dos jogadores não foram associados com o IPTO moderado.

\section{Comparação do Índice de Performance Tática Ofensiva (IPTO) entre alto e baixo}

Foi observado que para o princípio "cobertura ofensiva" foi encontrada associação positiva entre a eficiência do comportamento tático e IPTO alto (TABELA 1). Sendo que, os jogadores que obtiveram eficiência moderada para este princípio, possuem entre $<0,1$ e 0,5 vezes mais chances de aumentarem seu IPTO de baixo para alto. Além disso, os jogadores que obtiveram eficiência alta para este princípio, possuem entre $<0,1$ e 0,6 vezes mais chances de aumentarem seu IPTO de baixo para alto. Resultados similares foram encontrados para o princípio "unidade ofensiva", onde os jogadores que obtiveram eficiência moderada para este princípio, possuem entre $<0,1$ e 0,9 vezes mais chances de aumentarem seu IPTO de baixo para alto. Além disso, os jogadores que obtiveram eficiência alta para este princípio, possuem entre $<0,1$ e 0,7 vezes mais chances de aumentarem seu IPTO de baixo para alto. A eficiência do comportamento tático para os princípios "penetração", "mobilidade", "espaço" e o quartil de nascimento dos jogadores não foram associados com o IPTO alto.

\section{Comparação do Índice de Performance Tática Defensiva (IPTD) entre moderado e baixo}

Foi observado que para o princípio "equilíbrio" foi encontrada associação positiva entre a eficiência do comportamento tático e IPTD moderado (TABELA 2). Sendo que, os jogadores que obtiveram eficiência moderada para este princípio possuem entre $0,1 \mathrm{e}$ 0,8 vezes mais chances de aumentarem seu IPTD de baixo para moderado. Resultados similares foram encontrados para o princípio "unidade defensiva", onde os jogadores que obtiveram eficiência moderada para este princípio possuem entre $<0,1$ e 0,4 vezes mais chances de aumentarem seu IPTD de baixo para moderado. A eficiência do comportamento tático para os princípios "contenção", "cobertura defensiva", "concentração" e os quartis de nascimento dos jogadores não foram associados com o IPTD moderado (TABELA 2).

\section{Comparação do Índice de Performance Tática Defensiva (IPTD) entre alto e baixo}

Foi observado que a data de nascimento está associada positivamente com o IPTD moderado (TABELA 2). Sendo que, os jogadores que nasceram no segundo quartil (Abril - Junho) possuem 1,5 e 50,3 vezes mais chances de aumentarem seu IPTD de baixo para alto. Também foi verificada associação positiva entre a eficiência do comportamento tático e IPTD alto para o princípio "cobertura defensiva". Sendo que, os jogadores que obtiveram eficiência alta para este princípio possuem entre $<0,1$ e 0,8 vezes mais chances de aumentarem seu IPTD de baixo para alto. Também foi observada associação positiva entre a eficiência do comportamento tático e IPTD alto para o princípio "equilíbrio". Sendo que, os jogadores que obtiveram eficiência moderada possuem entre $<0,1$ e 0,3 chances de aumentarem seu IPTD de baixo para alto. Além disso, os jogadores que obtiveram eficiência alta para este princípio, possuem entre $<0,1$ e 0,5 vezes mais chances de aumentarem seu IPTD de baixo para alto. Também foi verificada associação positiva entre a eficiência do comportamento tático e IPTD alto para o princípio "unidade defensiva". Sendo que, os jogadores que obtiveram eficiência moderada possuem até $<0,1$ mais chances de aumentarem seu IPTD de baixo para alto. Além disso, os jogadores que obtiveram eficiência alta para este princípio possuem entre $<0,1$ e 0,4 vezes mais chances de aumentarem seu IPTD de baixo para alto. A eficiência do comportamento tático para os princípios "contenção" e "concentração" não foram associados com o IPTD alto. 
TABELA 1 - Porcentagem demoderado ealto do ÍndicedePerformance Tática Ofensiva(IPTO) efatores associados ao IPTO.

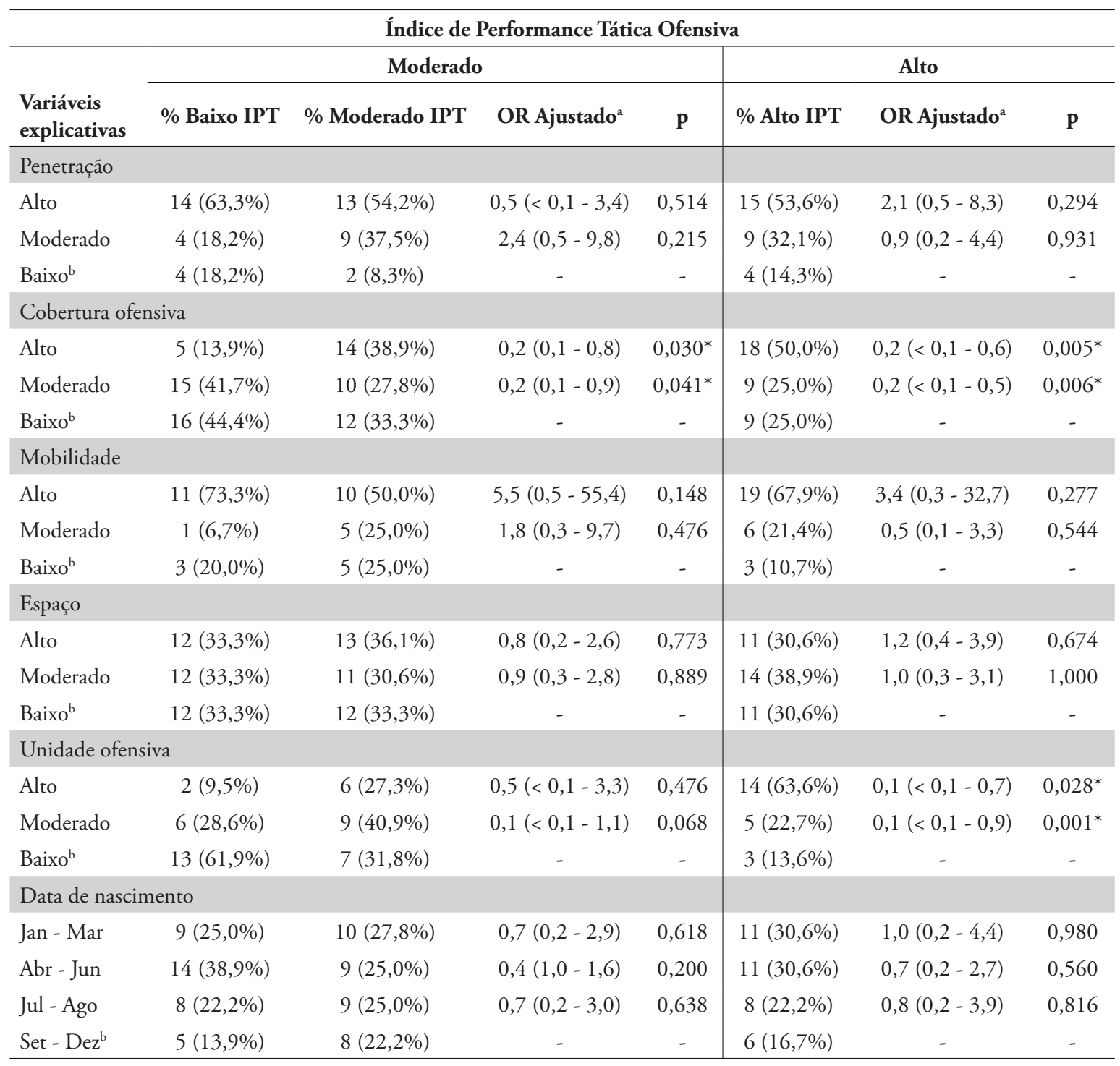

TABELA 2 - Porcentagem de moderado e alto do Índice de Performance Tática Defensiva (IPTD) e fatores associados ao IPTD.

\begin{tabular}{|c|c|c|c|c|c|c|c|}
\hline \multicolumn{8}{|c|}{ Índice de Performance Tática Defensiva } \\
\hline \multirow{2}{*}{$\begin{array}{l}\text { Variáveis } \\
\text { explicativas }\end{array}$} & \multicolumn{4}{|c|}{ Moderado } & \multicolumn{3}{|c|}{ Alto } \\
\hline & \% Baixo IPT & \% Moderado IPT & OR Ajustado $^{a}$ & $\mathbf{p}$ & $\%$ Alto IPT & OR Ajustado $^{\mathrm{a}}$ & $\mathbf{p}$ \\
\hline \multicolumn{8}{|l|}{ Contenção } \\
\hline Alto & $4(21,1 \%)$ & $10(33,3 \%)$ & $1,2(0,2-6,1)$ & 0,825 & $8(33,3 \%)$ & $1,4(0,3-7,2)$ & 0,707 \\
\hline Moderado & $4(21,1 \%)$ & $12(40,0 \%)$ & $0,3(0,1-1,3)$ & 0,101 & $11(45,8 \%)$ & $0,2(<0,1-1,1)$ & 0,069 \\
\hline Baixo $^{b}$ & $11(57,9 \%)$ & $8(26,7 \%)$ & - & - & $5(20,8 \%)$ & - & - \\
\hline \multicolumn{8}{|c|}{ Cobertura defensiva } \\
\hline Alto & $7(29,2 \%)$ & $11(45,8 \%)$ & $0,4(0,1-1,7)$ & 0,241 & $15(62,5 \%)$ & $0,2(<0,1-0,8)$ & $0,025^{*}$ \\
\hline Moderado & $10(41,7 \%)$ & $7(29,2 \%)$ & $0,5(0,1-2,3)$ & 0,411 & $4(16,7 \%)$ & $0,3(0,1-1,4)$ & 0,139 \\
\hline Baixo $^{\text {b }}$ & $7(29,2 \%)$ & $6(25,0 \%)$ & - & - & $5(20,8 \%)$ & - & - \\
\hline
\end{tabular}

${ }^{a}$ Odds Ratio Ajustado para todas as variáveis do modelo (principais efeitos);

${ }^{b}$ Referência Categórica: Baixo e Set-Dez; *Diferença significativa $(p<0,05)$.

para todas as variáveis do modelo (principais ${ }^{b}$ Referência Categórica: Baixo e Set-Dez; *Diferença significativa $(p<0,05)$.

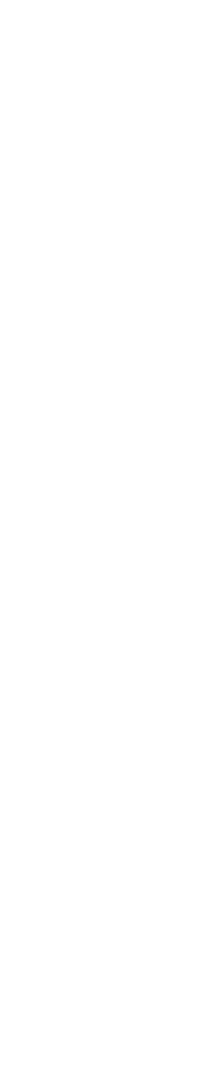


TABELA 2 - Porcentagem de moderado e alto do Índice de Performance Tática Defensiva (IPTD) e fatores associados ao IPTD. (continuação).

aOdds Ratio Ajustado para todas as variáveis do modelo (principais efeitos);

${ }^{\text {b} R e f e r e ̂ n c i a ~ C a t e g o ́ r i c a: ~}$ Baixo e Set-Dez; *Diferença significativa $(p<0,05)$.

\begin{tabular}{|c|c|c|c|c|c|c|c|}
\hline \multicolumn{8}{|c|}{ Índice de Performance Tática Defensiva } \\
\hline \multirow{2}{*}{$\begin{array}{l}\text { Variáveis } \\
\text { explicativas }\end{array}$} & \multicolumn{4}{|c|}{ Moderado } & \multicolumn{3}{|c|}{ Alto } \\
\hline & \% Baixo IPT & \% Moderado IPT & OR Ajustado ${ }^{\mathrm{a}}$ & $\mathbf{p}$ & $\%$ Alto IPT & OR Ajustado ${ }^{a}$ & $\mathbf{p}$ \\
\hline \multicolumn{8}{|l|}{ Equílibrio } \\
\hline Alto & $4(11,1 \%)$ & $13(34,2 \%)$ & $0,3(0,1-1,0)$ & 0,055 & $19(55,9 \%)$ & $0,1(<0,1-0,5)$ & $0,003^{*}$ \\
\hline Moderado & $14(38,9 \%)$ & $12(31,6 \%)$ & $0,2(<0,1-0,8)$ & $0,026^{*}$ & $8(23,5 \%)$ & $0,1(<0,1-0,3)$ & $<0,001^{*}$ \\
\hline Baixo $^{b}$ & $18(50,0 \%)$ & $13(34,2 \%)$ & - & - & $7(20,6 \%)$ & - & - \\
\hline \multicolumn{8}{|c|}{ Concentração } \\
\hline Alto & $13(56,5 \%)$ & $11(50,0 \%)$ & $2,3(0,4-15,4)$ & 0,369 & $12(57,1 \%)$ & $1,0(0,1-8,9)$ & 0,941 \\
\hline Moderado & $2(8,7 \%)$ & $4(18,2 \%)$ & $1,0(0,3-3,8)$ & 0,959 & $2(9,5 \%)$ & $0,9(0,3-3,4)$ & 0,935 \\
\hline Baixo $^{b}$ & $8(34,8 \%)$ & $7(31,8 \%)$ & - & - & $7(33,3 \%)$ & - & - \\
\hline \multicolumn{8}{|c|}{ Unidade defensiva } \\
\hline Alto & $1(2,8 \%)$ & $11(28,9 \%)$ & $0,1(<0,1-1,1)$ & 0,070 & $21(61,8 \%)$ & $<0,1(<0,1-0,4)$ & $0,006^{*}$ \\
\hline Moderado & $11(30,6 \%)$ & $16(42,1 \%)$ & $<0,1(<0,1-0,4)$ & $0,004^{*}$ & $11(32,4 \%)$ & $<0,1(<0,1-<0,1)$ & $<0,001^{*}$ \\
\hline Baixo $^{b}$ & $24(66,7 \%)$ & $11(28,9 \%)$ & - & - & $2(5,9 \%)$ & - & - \\
\hline \multicolumn{8}{|c|}{ Data de nascimento } \\
\hline Jan - Mar & $11(30,6 \%)$ & $9(23,7 \%)$ & $1,1(0,3-4,3)$ & 0,815 & $10(29,4 \%)$ & $4,5(0,8-25,9)$ & 0,089 \\
\hline Abr - Jun & $8(22,2 \%)$ & $12(31,6 \%)$ & $2,1(0,6-8,0)$ & 0,257 & $14(41,2 \%)$ & $8,7(1,5-50,3)$ & $0,015^{*}$ \\
\hline Jul - Ago & $7(19,4 \%)$ & $10(26,3 \%)$ & $2,0(0,5-8,0)$ & 0,306 & $8(23,5 \%)$ & $5,7(0,9-35,4)$ & 0,061 \\
\hline Set $-\mathrm{Dez}^{\mathrm{b}}$ & $10(27,8 \%)$ & $7(18,4 \%)$ & - & - & $2(5,9 \%)$ & - & - \\
\hline
\end{tabular}

\section{Discussão}

O objetivo deste estudo foi verificar como a eficiência do comportamento tático e a data de nascimento podem condicionar o desempenho tático de jogadores de futebol.

Os resultados indicaram associaçôes positivas entre a eficiência do comportamento tático e o Índice de Performance Tática Ofensiva para os princípios "cobertura ofensiva" e "unidade ofensiva". Para o Índice de Performance Tática Defensiva foram verificadas associaçóes positivas no que refere a eficiência do comportamento para os princípios táticos "cobertura defensiva", "equilíbrio" e "unidade defensiva". Em relação ao efeito da idade relativa, foi verificado associação positiva entre a data de nascimento e o desempenho tático dos jogadores nascidos no segundo quartil para o Índice de Performance Tática Defensiva.

No que refere o Índice de Performance Tática Ofensiva, os achados mostraram que os princípios que obtiveram associação positiva com a eficiência do comportamento tático (cobertura ofensiva e unidade ofensiva) devem possuir o foco no processo de ensino/treino, uma vez que, os resultados sugerem que a maior eficiência do comportamento tático para estes princípios acarretará em mudanças significativas no desempenho tático dos jogadores. Estes por sua vez, referem-se a princípios que demandam de ações que ofereçam apoio ao portador da bola e possibilitem aos jogadores a aproximaçáo do centro de jogo, ocasionando uma racionalização do espaço de jogo, visto que, os jogadores com a faixa etária entre 14 a 15 anos, em muitas vezes, possuem o foco na bola e não se atentam às informaçóes relevantes do jogo, apresentando dificuldades em comportamentos que ofereçam a continuidade das jogadas ofensivas ${ }^{20}$.

A execução eficiente destes dois princípios acarretará no oferecimento constante das linhas de passe ao portador da bola e na aproximação dos jogadores para possibilitar jogar em bloco. A partir disso, treinamentos que desenvolvam essas capacidades, poderão proporcionar a melhoria dos jogadores na gestão do espaço de jogo, implicando diretamente no sucesso das açóes táticas dos jogadores ${ }^{21}$.

A respeito do Îndice de Performance Tática Defensiva, os achados mostraram que as associaçôes 
positivas com a eficiência do comportamento tático encontradas foram observadas para os princípios "cobertura defensiva", "equilíbrio" e "unidade defensiva", onde se trata de princípios com maior complexidade, que demandam de um maior conhecimento do espaço de jogo, além de serem princípios que dependem do posicionamento dos outros jogadores para sua realização $\mathrm{O}^{22}$. Muitas vezes, os jogadores focam-se na bola e na proteçáo a baliza e não se atentam aos princípios que demandam de uma maior organização espacial ${ }^{2,20}$.

Os princípios "cobertura defensiva", "equilíbrio" e "unidade defensiva" relacionam-se com a noção de estabilidade defensiva, da proteção à baliza com atenção aos não portadores da bola e da organização espacial com o intuito de gerar imprevisibilidade ao adversário ${ }^{20,23-24}$. Os resultados deste trabalho indicam que a melhora da eficiência do comportamento tático para estes princípios poderá acarretar mudanças significativas no desempenho dos jogadores, visto que são princípios que os jogadores de 14 a 15 anos apresentam dificuldades em sua realização, prejudicando a construção de açôes ofensivas e, como consequência, a continuidade das jogadas.

Nesta perspectiva, a literatura destaca que no processo de formação de jogadores, a categoria Sub-15 encontra-se na transição entre as fases de orientação e direção. Neste período, o jogador se encontra em desenvolvimento quanto à organizaçấo do espaço de jogo, visto que essa organização espacial é condição fundamental a ser treinada para esta categoria ${ }^{14,25}$.

Além dos aspectos táticos, os resultados deste estudo apontaram que os jogadores nascidos no primeiro semestre do ano, possuem vantagens no que se refere o Índice de Performance Tática Defensiva em relação aos jogadores nascidos no segundo semestre, corroborando os estudos que comprovam a existência do efeito da idade relativa no futebol ${ }^{9,11-12}$. Além disso, estes achados corroboram o estudo de TeOLdo et al. ${ }^{5}$, em qual, destacam que os jogadores nascidos no primeiro trimestre obtiveram vantagens em relação ao desempenho de açóes táticas relacionadas aos princípios táticos defensivos. Estes resultados podem ser explicados pela especificidade dos princípios táticos da fase defensiva, que são mais exigentes em termos físicos do que os princípios táticos da fase ofensiva ${ }^{5,26-27}$. Assim, no processo de seleção de talentos, jogadores que nascem nos primeiros meses do ano tendem a levar vantagem no processo de seleção em relação aos jogadores nascidos nos últimos meses, pois, podem apresentar capacidades físicas e técnicas mais elevadas que seus pares ${ }^{5,28}$. Portanto, essas capacidades mais elevadas podem interferir diretamente no desempenho tático dos jogadores, no qual para este estudo, foram apresentadas diferenças significativas na fase defensiva de jogo.

A partir disso, em relação à gestão do espaço no campo de jogo, enfatiza-se a necessidade do desenvolvimento de treinamentos para os aspectos táticos, em especial das açóes que preconizem a gestáo do espaço do jogo através de maior compactação dos jogadores (jogo em blocos), da diminuição de espaço entre os jogadores e do reforço quanto à marcação das linhas de passe da equipe adversária ${ }^{24,29}$.

De forma geral, os resultados apresentados neste trabalho oferecem informaçóes importantes para treinadores e pesquisadores que atuam na categoria Sub-15, direcionando os profissionais quanto à sistematizaçáo do treinamento e ao processo de agrupamento dos jogadores nesta fase de formação. Essas informações pautaram-se em identificar os princípios que devem receber uma maior atenção no processo de treinamento da categoria em específico, além de avançar com os estudos sobre o efeito da idade relativa nas categorias de formaçáo no futebol.

Os resultados deste estudo mostraram associaçóes positivas entre a eficiência do comportamento tático e o desempenho tático dos jogadores, além de verificar associação positiva entre a data de nascimento e o Índice de Performance Tática Defensiva dos jogadores.

Conclui-se que tanto para os jogadores que apresentaram melhor eficiência para os comportamentos táticos "cobertura ofensiva", "unidade ofensiva", "cobertura defensiva", "equilíbrio" e "unidade defensiva" quanto àqueles que nasceram no segundo quartil, possuem maiores chances de apresentarem o Índice de Performance Tática mais elevado, quando comparado com os demais jogadores da categoria Sub-15 analisada neste estudo.

Por fim, sugere-se o desenvolvimento deste tipo de estudo considerando o tempo de prática dos jogadores, a fim de verificar a influência desta variável na componente tática do futebol em diferentes categorias de formação. 


\begin{abstract}
How tactical behavior efficiency and birthdate affect performance of soccer players?

The aim of this study was to investigate how tactical behavior efficiency and birthdate affect the tactical performance of soccer players. The sample comprised 6640 tactical actions performed by 108 players of U-15. FUT-SAT was used to collect and analyze data. Birthdate was obtained through identity card or birth certificate. It was used descriptive analysis, Multinomial Logistic Regression $(p<0.05)$ and Cohen's Kappa tests. For statistical analysis, SPSS software was used. It was found positive associations between tactical behavior efficiency and tactical performance for the tactical principles "offensive coverage", "offensive unity", "defensive coverage", "balance" and "defensive unity". It was also observed positive associations between birthdate and Defensive Tactical Performance Index for players who were born within the second quartile. It is concluded that for this sample, tactical behavior efficiency and birthdate influenced tactical performance.
\end{abstract}

KEY WoRDS: Tactics; Relative age effect; Youth level; Sport development.

\title{
Referências
}

1. McPherson SL. The development of sport expertise: mapping the tactical domain. Quest. 1994;46:223-40.

2. Garganta J. Modelação táctica do jogo de futebol: estudo da organizaçáo da fase ofensiva em equipas de alto rendimento [tese]. Porto (Portugal): Universidade do Porto; 1997.

3. Gréhaigne JF, Godbout P, Bouthier D. Performance assessment in team sports. J Teach Phys Educ. 1997;16:500-16.

4. Côté J, Macdonald DJ, Baker J, Abernethy B. When "where" is more important than "when": birthplace and birthdate effects on the achievement of sporting expertise. J Sports Sci. 2006;24:1065-73.

5. Teoldo I, Garganta J, Greco PJ, Mesquita I, Seabra A. Influence of relative age effects and quality of tactical behaviour in the performance of youth soccer players. Int J Perform Anal Sport. 2010;10:82-97.

6. Mesquita I. The multidimensionality in the domain of the volleyball skills. In: Hughes M, Tavares F, editors. Notational analysis of sport IV. Porto: Centre for Team Sports Studies, Faculty of Sports Sciences and Physical Education, University of Porto; 1998. p.147-55.

7. Malina RM, Eisenmann JC, Cumming SP, Ribeiro B, Aroso J. Maturity-associated variation in the growth and functional capacities of youth football (soccer) players 13-15 years. Eur J Appl Physiol. 2004;91:555-62.

8. Abernethy B, Baker J, Côté J. Transfer of pattern recall skills may contribute to the development of sport expertise. Appl Cognit Psychol. 2005;19:705-18.

9. Helsen WF, Winckel JV, Williams AM. The relative age effect in youth soccer across Europe. J Sports Sci. 2005;23:629-36.

10. Musch J, Grondin S. Unequal competition as an impediment to personal development: a review of the relative age effect in sport. Dev Rev. 2001;21:147-67.

11. Barnsley R, Thompson AH, Legault P. Family planning: football style: the relative age effect in football. Int Rev Sociol Sport. 1992;27:78-86.

12. Musch J, Hay R. The relative age effect in soccer: cross-cultural evidence for a systematic discrimination against children born late in the competition year. Sociol Sport J. 1999;16:54-64.

13. Moraes LC, Penna EM, Ferreira RM, Costa VT, Matos AF. Análise do quartil de nascimento de atletas profissionais de futebol. Pensar Prát. 2009;12:1-9.

14. Greco PJ, Benda RN. Iniciação esportiva universal 1: da aprendizagem motora ao treinamento técnico. Belo Horizonte: Escola de Educação Física/UFMG; 1998.

15. Teoldo I, Garganta J, Greco PJ, Mesquita I. Princípios táticos do jogo de futebol: conceitos e aplicação. Motriz. 2009;15:657-68.

16. Teoldo I, Garganta J, Greco PJ, Mesquita I, Maia J. Sistema de avaliaçáo táctica no futebol (FUT-SAT): desenvolvimento e validação preliminar. Motricidade. 2011;7:69-84. 
17. Robinson G, O’Donoghue PG. A weighted kappa statistic for reliability testing in performance analyses of sport. Int J Perform Anal Sport. 2007;7:12-9.

18. Tabachnick B, Fidell L. Using multivariate statistics. New York: Harper \& Row; 2007.

19. Landis JR, Koch GG. The measurement of observer agreement for categorical data. Biometrics. 1977;33:159-74.

20. Garganta J, Pinto J. O ensino do futebol. In: Graça A, Oliveira J, editores. O ensino dos jogos desportivos. Porto: Faculdade de Ciências do Desporto e de Educação Física da Universidade do Porto; 1994. p.95-136.

21. Gréhaigne JF, Godbout P. Tactical knowledge in team sports from a constructivist and cognitivist perspective. Quest. 1995; 47:490-505.

22. Teoldo I. Comportamento tático no futebol: contributo para a avaliação do desempenho de jogadores em situaçôes de jogo reduzido [tese]. Porto (Portugal): Universidade do Porto, Faculdade de Desporto; 2010.

23. Garganta J, Gréhaigne JF. Abordagem sistêmica do jogo de futebol: moda ou necessidade? Movimento. 1999;10:40-50.

24. Teoldo I, Garganta J, Greco PJ, Mesquita I. Avaliação do desempenho tático no futebol: concepção e desenvolvimento da grelha de observação do teste "GR3-3GR". R Min Educ Fís. 2009;17:36-64.

25. Greco PJ. Iniciação esportiva universal 2: metodologia da iniciação esportiva na escola e no clube. Belo Horizonte: Escola de Educação Física/UFMG; 1998.

26. Vaeyens R, Philippaerts RM, Malina RM. The relative age effect in soccer: a match-related perspective. J Sports Sci. 2005;23:747-56.

27. Mujika I, Vaeyens R, Matthys SPJ, Santisteban J, Goiriena J, Philippaerts R. The relative age effect in a professional football club setting. J Sports Sci. 2009;27:1153-8.

28. Ford PR, Ward P, Hodges NJ, Williams AM. The role of deliberate practice and play in career progression in sport: the early engagement hypothesis. High Abil Stud. 2009;20:65-75.

29. Gréhaigne JF, Bouthier D, David B. Dynamic-system analysis of opponent relationships in collective actions in soccer. J Sports Sci. 1997;15:137-49.

\section{Agradecimentos}

À Fundação de Amparo à Pesquisa do Estado de Minas Gerais (FAPEMIG), à Coordenação de Aperfeiçoamento de Pessoal de Nível Superior (CAPES), ao Conselho Nacional de Desenvolvimento Científico e Tecnológico (CNPq), à Fundação Arthur Bernardes (FUNARBE), à Reitoria, à Pró-Reitoria de Pesquisa e Pós-Graduação e à Direção do Centro de Ciências Biológicas e da Saúde da Universidade Federal de Viçosa pelo apoio financeiro concedido a este estudo.

À Secretaria de Estado de Esportes e da Juventude do Estado de Minas Gerais pelo financiamento deste trabalho através da Lei Estadual de Incentivo ao Esporte.

\begin{tabular}{r|r} 
ENDEREÇO & \\
Marcelo Odilon Cabral de Andrade & \\
Núcleo de Pesquisa e Estudos em Futebol - NUPEF & \\
Departamento de Educação Física & \\
Centro de Ciências Biológicas e da Saúde & Recebido para publicação: 13/08/2013 \\
Universidade Federal de Viçosa & Revisado: 05/08/2014 \\
Av. P.H.Rolfs, s/ n. - Campus Universitário & Aceito: 03/01/2015 \\
36570-900 - Viçosa - MG - BRASIL & \\
e-mail: mocabral.andrade@gmail.com &
\end{tabular}

